\title{
La excepción de contrato no cumplido. Algunas cuestiones relativas a su supuesto de hecho y consecuencias jurídicas*
}

Exceptio non Adimpleti Contractus. Some Notes Relating to its Condition of Fact and Legal Consequences

Íñigo Andrés de la Maza-Gazmuri ${ }^{\text {a }}$

Universidad Diego Portales, Chile

DOI: https://doi.org/10.11144/Javeriana.vj139.ecnc

inigo.delamaza@udp.cl

ORCID: http://orcid.org/0000-0001-6239-2837

Recepción: 17 Mayo 2019

Álvaro Vidal-Olivares

Aceptación: 02 Junio 2019

Pontificia Universidad Católica de Valparaiso, Chile

ORCID: http://orcid.org/0000-0001-5362-9310

\section{Resumen:}

En este artículo se analiza el remedio de la suspensión del cumplimiento o excepción de contrato no cumplido en Chile. En particular, se examina el supuesto de hecho de este remedio contractual y sus particulares condiciones, para luego atender a los efectos de la figura, atendiendo, también, a la relación que existe entre esta y los restantes remedios frente al incumplimiento.

Palabras clave: Incumplimiento, contrato, excepción de contrato no cumplido, remedios del acreedor, suspensión del cumplimiento.

\section{Abstract:}

This article aims to analyze the remedy of the suspension of the compliance or exceptio non adimpleti contractus. In particular, considering the factual budget of the contractual remedy, its particular conditions, to then attend to the effects of this remedy, also attending to the relationship that exists between it and the other remedies against the breach of contract.

Keywords: Breach of contract, contract, exceptio non adimpleti contractus, creditor remedies, suspension of fulfillment.

\section{Ideas previas}

Como en todos los códigos decimonónicos, en el Código Civil chileno no existe una regulación completa y sistemática de aquel remedio que, con denominaciones diversas - "excepción de contrato no cumplido" o "suspensión" - permite a una parte suspender el cumplimiento de su prestación mientras la otra parte no cumpla la propia en un contrato sinalagmático. Tal carencia de disciplina se refiere tanto al supuesto de hecho como a las consecuencias del remedio al que, en atención a la denominación que recibe en la doctrina nacional y no obstante lo inadecuada que pueda resultar ${ }^{[1]}$, nos referiremos en adelante como "excepción de contrato no cumplido".

El vacío apuntado no significa, sin embargo, que en el Código Civil no exista ningún material pertinente, sino, más bien, que ese material resulta deficiente para construir tanto el supuesto de hecho como las consecuencias jurídicas de la aplicación del remedio. Existen al menos tres disposiciones particulares en el Código Civil que han servido de fundamento a su desarrollo doctrinario y jurisprudencial. Se trata del artículo 1552 (1609 del Código colombiano) con ocasión de la mora en los contratos bilaterales, el inciso final del artículo 1826 (1882 del Código colombiano) respecto del incumplimiento de las obligaciones del comprador; asimismo, ha de considerarse el artículo 2158 (2184 del Código colombiano), a propósito de las obligaciones del mandante ${ }^{[2]}$.

Notas de autor

\footnotetext{
a Autor de correspondencia. Correo electrónico: inigo.delamaza@udp.cl
} 
La primera de las normas enumeradas, sin duda, ha sido la de mayor relevancia, pues a partir de su configuración tanto la academia como los tribunales han formulado un remedio de extensión general; uno que, por cierto, se constituye como una de las alternativas de defensa ante la pretensión de cumplimiento en naturaleza, la demanda resolutoria o la acción de daños contractuales.

Conviene en este punto atender al fundamento de la excepción de contrato no cumplido, toda vez que ello permitirá clarificar la comprensión de esta institución como remedio del acreedor en cuanto a la facultad de suspender su propio cumplimiento, como hoy lo concibe el nuevo derecho de los contratos o la moderna dogmática contractual ${ }^{[3]}$.

Bien sabemos que todo contrato bilateral obliga a ambas partes recíprocamente, produciendo obligaciones interdependientes entre sí. La obligación que nace para una de las partes encuentra su causa (causa final) ${ }^{[4]}$, a su turno, en la obligación correlativa de la otra, al punto que ninguna de ellas se explica sin la otra. Por muy abstracto que nos parezca, esta es la explicación de los llamados efectos particulares de esta especie de contratos en caso de incumplimiento de uno de los contratantes, efectos entre los que se incluye la excepción de contrato no cumplido ${ }^{[5]}$. En estas convenciones, el incumplimiento, en sentido amplio ${ }^{[6]}$, necesariamente repercute en el contrato y, más precisamente, en la posición de la otra parte. Así, en lo que a nosotros nos interesa, si una parte incumple, la exigibilidad de la obligación de la otra se suspende, actuando como una genuina excusa de cumplimiento para la otra parte afectada y reconociéndosele la facultad de suspensión del mismo, la que nuestro derecho decimonónico concibe como excepción, aunque hoy también puede desenvolverse como acción desde su comprensión de remedio contractual. Es, precisamente, la interdependencia de las obligaciones recíprocas la que explica este efecto de suspensión de los efectos de la convención ${ }^{[7]}$.

Llegados a este punto, podemos precisar la primera idea, esto es, que en los contratos bilaterales una parte se obliga para con el otro, porque éste, a su vez, contrae una obligación con el primero. Lo cierto es que, lo que resulta especialmente relevante y que explica la excepción de contrato no cumplido en todo contrato de esta naturaleza, como los otros efectos particulares, no es tanto que la otra parte se obligue, sino más bien que esa parte que se obliga cumpla el contrato fiel y oportunamente ${ }^{[8]}$.

En lo que concierne al objeto este artículo, pretendemos demostrar que el fundamento de la excepción de contrato no cumplido es aquel principio de la simultaneidad en el cumplimiento de las obligaciones ${ }^{[9]}$, que no es otra cosa que lo anunciado antes: una parte cumple en la medida que la otra lo hace y si esta última no lo hace, la primera queda facultada para suspender su propio cumplimiento.

Entendido así el fundamento, podemos observar cómo se plasma la figura en el derecho uniforme de contratos. Este ejercicio es relevante, desde que permite comprender con mayor claridad por qué se ha calificado ya no como una "excepción", con la carga adjetiva y procesal que ello comporta, sino como un remedio contractual; como una medida que el contrato prevé para el caso del incumplimiento a favor del acreedor afectado, y que se traduce en la facultad de que dispone unos de los contratantes de suspender su propio cumplimiento $^{[10]}$.

La Convención de las Naciones Unidas sobre los contratos de compraventa internacional de mercaderías $(\mathrm{CISG})^{[11]}$, por ejemplo, establece en su artículo 71 que ambas partes disponen de la facultad de diferir la ejecución de sus obligaciones con posterioridad a la celebración del contrato si se advierte palmariamente que su contraparte no dará cumplimiento sustancial a sus obligaciones ${ }^{[12]}$.

Otro tanto sucede con los Principios de Unidroit (PICC) que recogen en su artículo 7.1.3 la suspensión del cumplimiento para los casos en que 1) las partes cumplen simultáneamente sus obligaciones, en cuyo caso, una parte podrá suspender el cumplimiento de su obligación mientras su cocontratante no ofrezca su prestación, o 2) en la hipótesis en que las partes cumplen sucesivamente sus obligaciones, caso en el cual podrá una de ellas suspender en tanto la otra lo haga primero ${ }^{[13]}$.

La figura también ha sido acogida en los Principios Latinoamericanos de Derecho de Contratos (PLDC). En su artículo 102 precisa que cada una de las partes podrá negarse a dar cumplimiento a sus obligaciones en 
tanto que la otra no lo haga, salvo que por su naturaleza o por acuerdo de los mismos contratantes la ejecución de las obligaciones de una de ellas deba tener lugar antes que la otra ${ }^{[14]}$.

Cada uno de los cuerpos de derecho uniforme citados prevén la excepción de contrato no cumplido o suspensión del cumplimiento, bajo el acápite de los remedios frente al incumplimiento. Por lo demás, en los comentarios al artículo 7.1.3 de los PICC se indica explícitamente que la aludida norma debe necesariamente leerse o relacionarse con los remedios. En este señala que:

This Article must be read together with Article 6.1.4 (Order of performance). This Article is concerned with remedies and corresponds in effect to the civil law concept of exceptio non adimpleti contractus ${ }^{[15]}$.

Sirva también para ilustrar lo que se viene sosteniendo lo que disponen, por su parte, los códigos civiles $\operatorname{argentino~}^{[16]}$ y francés, recientemente reformados. El primero establece en su artículo 1031 la suspensión del cumplimiento, se señala que:

En los contratos bilaterales, cuando las partes deben cumplir simultáneamente, una de ellas puede suspender el cumplimiento de la prestación, hasta que la otra cumpla u ofrezca cumplir”. El Código francés, en tanto, dispone en su artículo 1219 que: "Una parte podrá rehusar cumplir su obligación, aun cuando ésta sea exigible, si la otra no cumple la suya y si dicho incumplimiento es suficientemente grave ${ }^{[17]}$.

Como vemos, en la mentada legislación comparada se concibe a la excepción de contrato no cumplido dentro de la disciplina de los efectos del del contrato y de su incumplimiento. Es decir, se le ubica dentro del conjunto de los remedios al incumplimiento de que dispone el acreedor y que se concreta, al igual que en derecho uniforme y armonizado de contratos, como una facultad de suspender el cumplimiento del contrato.

Expuesto el panorama, nos proponemos avanzar en la determinación del supuesto de hecho de la excepción de contrato no cumplido, y sus consecuencias jurídicas.

\section{Supuesto de hecho}

Al hacer uso de la voz "supuesto de hecho", pretendemos referirnos al conjunto de condiciones que hacen procedente el remedio. El supuesto puede ser expresado con precisión, entendiendo que se constituye cuando las partes concernidas incumplen lo que ellas mismas han convenido en virtud del contrato. La figura en examen tiene por base la existencia de incumplimientos recíprocos, independientemente de la relación que entre ellos puede mediar.

Existe debate en torno a su ámbito de aplicación, pues se ha estimado, por unos, que la excepción de contrato no cumplido procede solo en presencia de incumplimientos en contratos bilaterales, y por otros se ha entendido que es posible extenderla a otras hipótesis distintas ${ }^{[18]}$. Sin perjuicio de lo antes advertido, el alcance de este artículo sólo se ocupa de los casos de contratos bilaterales ya que, muy probablemente, ha sido con ocasión de su estudio que se ha presentado mayor debate, sobre todo en la Corte Suprema y los tribunales de alzada.

En este apartado nos interesa prestar atención a tres cuestiones que se han suscitado a propósito de la determinación del supuesto de hecho de la excepción de contrato no cumplido. La primera de ellas refiere a las obligaciones actualmente exigibles; la segunda, a la relación causal de ambos incumplimientos; y la tercera, a la buena fe y la proporcionalidad.

\section{Obligaciones actualmente exigibles}

Tratándose de los contratos bilaterales, puede afirmarse con seguridad que el fundamento de la excepción de contrato no cumplido se halla en la interdependencia de las obligaciones. Ante el incumplimiento de una 
de las partes, la otra no se ve compelida a hacerlo. En el lenguaje contemporáneo, esta última se encuentra excusada de cumplir lo pactado en tanto la primera no cumpla o no esté llana a cumplir.

En consecuencia, al tiempo de oponer la excepción como defensa ante el ejercicio de otros remedios, la obligación en contra de quien se deduce ha de serle actualmente exigible puesto que, de lo contrato, ¿cómo podría alegarse su incumplimiento ${ }^{[19]}$.

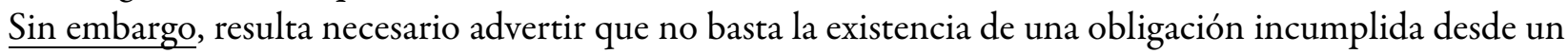
punto de vista objetivo; también es necesario que la ejecución de aquella obligación sea exigible. En este orden de ideas, por ejemplo, para evaluar un caso al que luego recurriremos, una parte se obliga a entregar a otra un semirremolque y su contraparte a pagarlo en dinero dentro de cierto plazo. Quien debe la entrega cumple imperfectamente; el comprador, en tanto, no realiza del pago en el término convenido y, por consiguiente, objetivamente, incurre en un incumplimiento contractual. No obstante, conforme nos parece, no es posible afirmar que la prestación a que se ha obligado el comprador -pagar el precio- fuera actualmente exigible. Por esta consideración, por ejemplo, si el comprador fuese quien hubiera pretendido obtener a través de demanda judicial, la sustitución del semirremolque defectuoso por otro que no lo sea conforme se pactó, más el resarcimiento de los perjuicios, y la parte vendedora opone la excepción de contrato no cumplido fundada en el incumplimiento de la obligación del comprador como defensa, ésta no prosperará porque esta última obligación no le era exigible.

Ahora bien, el hecho de que en un contrato sinalagmático se registren incumplimientos de ambas partes y que las obligaciones sean actualmente exigibles, no basta para responder a la pregunta respecto a si una parte puede oponer la excepción de contrato no cumplido. De esta manera, no parece adecuado que una parte cuyo incumplimiento ha determinado el de la contraria pueda interponerle la excepción de contrato no cumplido.

\section{Que un incumplimiento sea la causa del otro}

Conforme se ha pronunciado Claudia Mejías-Alonzo, el nexo causal se ha utilizado tanto para dar lugar como denegar la institución que nos ocupa ${ }^{[20]}$. Así, se ha fallado que no procede la excepción cuando el incumplimiento de quien la opone como defensa se funda en términos causales; vale decir, que dicho incumplimiento se haya producido por uno suyo que le preceda, dejando de ejecutar lo convenido.

Ante todo, hemos de distinguir la cuestión de la causalidad, por una parte, como elemento que integra el supuesto de hecho de la excepción de contrato no cumplido, de aquella referida a la conducta del acreedor \#acción u omisión\# como condición del cumplimiento de la otra parte, por la otra. Y esta conducta impuesta al acreedor en cuanto tal puede tener su origen en el propio contrato, o en la buena fe que le impone ciertos deberes de colaboración. No son propiamente obligaciones, sino más bien cargas contractuales del acreedor. Es por este orden de consideraciones que no pueden confundirse ambas hipótesis.

Sin embargo, Yusari no es de quienes lo aprecian de la referida forma, pues al desarrollar el criterio de la causalidad, recuerda el ejemplo de Clemente-Meoro acerca de un contrato de confección de vestuario, en donde una parte se ha obligado a entregar los diseños y la otra a confeccionar unas prendas teniendo por base tales bocetos. Estos autores estiman se estaría frente a un caso de incumplimientos recíprocos (excepción de contrato no cumplido, resultando evidente para ellos que, si la parte que ordenó la confección no entrega los diseños, la otra que se obligó a confeccionar las prendas tampoco estará en condiciones de cumplir con su obligación ${ }^{[21]}$. Con todo, nuestra opinión para este caso no es una en que el incumplimiento de una parte se funda causalmente en el de la otra, sino más bien en que es la conducta del acreedor, plasmada por su omisión, la que impide que el deudor ejecute la obligación que por el contrato ha contraído.

Podemos hallar expresada claramente esta distinción en los PICC (artículo 7.1.3), en los Principios Europeos de Derecho de Contratos (PECL; artículo 9:201) ${ }^{[22]}$ y los PLDC (artículos 91 y 102). Estos instrumentos regulan el supuesto en que el incumplimiento tenga su causa en la conducta del acreedor 
\#sea esta acción u omisión\#, y la solución que se consagra es la de privarle del derecho a invocar dicho incumplimiento en contra de su cocontratante y, seguidamente, de cualquier remedio contractual. Esta regla tiene por antecedente la constada en el artículo 80 de la CISG. A título ejemplar, el artículo 88 (Acción u omisión del acreedor) de los PLDC prescribe que "El acreedor no puede invocar el incumplimiento causado por su propia acción u omisión” ${ }^{[23]}$.

A propósito de esta regla, en otra oportunidad tuvimos ocasión de expresar que "La norma del artículo 88 se refiere a aquellos casos en los que el incumplimiento es absolutamente imputable al acreedor, sea que se trate de la inobservancia de un deber contractualmente pactado o que éste fluya de la propia naturaleza de la obligación por aplicación del principio de la buena fe en función de interpretación integradora. Es una regla de sentido común y que es una evidente concreción de la doctrina de los actos propios, porque precisamente se está reprimiendo la contradicción de una conducta anterior propia, la del acreedor que habiendo provocado exclusivamente el incumplimiento, ahora pretende demandar al deudor por tal incumplimiento, ejercitando un remedio o medio de tutela" ${ }^{\text {[24] }}$.

Si observamos nuestro ordenamiento, podría arribarse a la misma solución recurriendo a la regla de causalidad contenida en el artículo 1558, o bien a partir de la regla del artículo 1546 del Código Civil, continente del principio de buena fe como deber de colaboración ${ }^{[25]}$.

Volvamos ahora a considerar la causalidad en tanto criterio dirimente en la admisión o rechazo de la excepción de contrato no cumplido, e ilustremos cómo se desenvuelve en uno y otro sentido (para rechazar y para acoger.

Primeramente, tengamos en mente un caso en el que quien demanda por incumplimiento contractual es la parte que, a su vez, dejó de ejecutar lo convenido, dando lugar al incumplimiento de su contraparte. Esta es la hipótesis que recoge el fallo de la Corte Suprema de 31 de octubre de 2012. Conforme los hechos, el vendedor entregó mercaderías con anomalías materiales. Acto seguido, opuso al comprador, entre otras defensas, la excepción de contrato no cumplido por no haber pagado el precio de la venta, solicitando el rechazo de la demanda de indemnización autónoma. La Corte Suprema, pronunciándose sobre el caso declara en su considerando $13^{\circ}$ :

Que tampoco se acogerá la excepción de contrato no cumplido, fundado en el artículo 1552 del Código Civil, basado en el hecho de que la actora adeuda parte del precio convenido en la compraventa, porque la demanda de autos se basa en que las cosas vendidas no reunían las calidades que se habían convenido, lo que le ha supuesto perjuicios, por lo que parece perfectamente esperable que en esas circunstancias se haya suspendido el pago del saldo de precio. Cuando la demandante debió pagar el saldo de precio, la demandada ya había incurrido en el incumplimiento que por este juicio se le reprocha ${ }^{[26]}$.

En segundo término, resulta procedente pensar un caso en que el nexo causal actúe en el sentido opuesto, en otras palabras, en el que ella faculta a defenderse con la excepción de contrato no cumplido. Sirve para ilustrar aquello la decisión contenida en la sentencia de la Corte Suprema de 24 de marzo de $2011^{[27]}$. Se trata de un contrato de compraventa de unos semirremolques tolva, ejemplo que prevenimos con precedencia. Aquellos no cumplían con las especificaciones acordadas por las partes. Fruto de ello, frente a la demanda de pago del precio interpuesta por el vendedor, el comprador opuso como defensa la excepción en comento. El tribunal estimó procedente la defensa en virtud del carácter exigible de las obligaciones recíprocas, estando de buena fe quien excepciona y siendo el incumplimiento que alega una falta o infracción contractual que se constituye en su favor. Se termina por concluir en el fallo que, conforme la equidad, la buena fe y la causalidad, el incumplimiento de la parte demandante, recayó sobre una obligación relevante y de real trascendencia, ya que el desentendimiento de las especificaciones técnicas tornó ostensiblemente inútiles los bienes objeto de la compraventa ${ }^{[28]}$.

Entonces, podemos formularnos la siguiente pregunta: ¿por qué el comprador no pagó el precio al vendedor? Nos parece que la respuesta, con base en la interpretación que se propone de la sentencia de la Corte, es que la obligación vinculada al pago referido fue incumplida en primer término por el vendedor; en 
este sentido, puede decirse que el incumplimiento de la obligación del vendedor causó el incumplimiento de la del comprador.

En este sentido, una cuestión que ha de considerarse llegado a este punto es si acaso la causalidad, en tanto criterio que justifica acoger la excepción de contrato no cumplido, integra en todo caso su supuesto de hecho. Y la respuesta, nos parece, es que no necesariamente. Resulta perfectamente plausible que no podamos hablar de relación de causalidad entre los incumplimientos y aun así sea procedente la excepción. Así será, por ejemplo, cuando existe incumplimiento simultáneo de ambas partes, en cuyo caso ¿cómo podría afirmarse que uno es causa del otro?

En este orden, consideremos, con los matices necesarios, los hechos de una sentencia de la Corte Suprema de 4 de diciembre $2003^{[29]}$. Se trataba de un contrato de promesa de compraventa en el que una parte se obligó a reunir en su totalidad los derechos en una sucesión y la otra a obtener el dinero necesario \#por medio de un mutuo\# para saldar el monto convenido por precio. Ambas obligaciones se entendieron como exigibles en un mismo momento y fueron incumplidas en dicho instante ${ }^{[30]}$.

En casos como los que se presentan resulta indudable que, por una parte, no se puede aseverar que un incumplimiento sea causa del otro; no obstante, según creemos, tampoco puede afirmarse que no tenga cabida la excepción de contrato no cumplido. En verdad, al menos tal y como hemos expuesto el caso, es un ejemplo suficientemente claro de procedencia.

Así las cosas, al explorar el vínculo causal, descubrimos que no necesariamente es parte del supuesto de hecho de la excepción de contrato no cumplido; ello, porque hay casos en los cuales la condición que concurre para configurar su supuesto de hecho es distinta: la de los incumplimientos simultáneos.

\section{Buena fe y proporcionalidad}

Ha sido indicado respecto de la resolución por incumplimiento que no todo incumplimiento, sino solamente aquellos que revisten la calificación de esenciales o resolutorios, permiten su procedencia.

Algún debate parecido se ha desarrollado en relación con la excepción de contrato no cumplido. Como sabemos, señala la regla del artículo 1552 del Código Civil que: "En los contratos bilaterales ninguno de los contratantes está en mora dejando de cumplir lo pactado, mientras el otro no lo cumple por su parte, o no se allana a cumplirlo en la forma y tiempo debidos" ${ }^{[31]}$.

La cuestión por considerar ahora nos lleva al siguiente interrogante: ¿qué alcanza a cubrir la expresión "dejando de cumplir lo pactado"? ¿Todo incumplimiento o, como acontece con la facultad resolutoria, es preciso calificar dicho incumplimiento? Y si requiere de calificación, entonces surge otra pregunta: ¿dicha calificación funciona de la misma forma que en el remedio resolutorio?

Para abordar la pregunta, tenemos advertir que el supuesto sobre el cual se construye no es el de un incumplimiento total; en tal hipótesis, no existe duda que la excepción tiene lugar. La procedencia, eso sí, deja de ser posible en ciertas de las variadas manifestaciones del cumplimiento defectuoso.

En Chile, parece predominar la idea de que no cualquier incumplimiento la permite, sino exclusivamente aquellos que resulten graves ${ }^{[32]} \mathrm{y}$, a veces, se ha estimado que el criterio para determinar la gravedad debiese

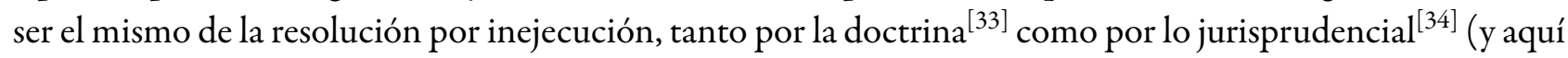
ha aparecido la segunda pregunta).

La jurisprudencia ha requerido que un incumplimiento revista de cierta magnitud y ello se ha justificado en la regla contractual de la buena fe objetiva. Al efecto, una sentencia de la Corte de Apelaciones de San Miguel, discutiendo sobre el incumplimiento de un contrato de arrendamiento de un bien raíz en el que la parte arrendataria denunciaba defectos en la cosa arrendada, el tribunal de segunda instancia consideró que, por las exigencias de la buena fe, el incumplimiento que funda la excepción de contrato no cumplida debe revestir de cierta gravedad ${ }^{[35]}$. 
Podría estimarse que cualquier incumplimiento que permita resolver el contrato faculta, al mismo tiempo, a oponer la excepción de contrato no cumplido. Sin embargo, al inverso las cosas no funcionan de la misma manera; es decir, no cualquier incumplimiento que justifica la excepción de contrato no cumplido permite declarar resuelto un contrato.

Claudia Mejías-Alonzo propone que, en principio, todo incumplimiento posibilita el ejercicio de la excepción de contrato no cumplido; no obstante, tal ejercicio no debe generar una colisión con la buena $\mathrm{fe}^{[36]}$. De esta forma, sugiere Mejías, el dispositivo de la buena fe permitiría distinguir entre aquellos incumplimientos de envergadura o de suficiente entidad para justificar la suspensión de la ejecución de lo pactado. Somos de la idea de pensar que se trata de una idea acertada; y sostenemos, tal como lo plantea esta autora, que la exigencia de proporcionalidad de los incumplimientos es una manifestación de los límites que impone la buena fe objetiva en el ejercicio de este remedio ${ }^{[37]}$.

Adicionalmente, en relación con lo ya dicho, la Corte Suprema en un fallo de 31 de marzo de 2003 ha resuelto en este sentido. En este caso, los contratantes incurrieron en incumplimientos recíprocos. Al efecto, el incumplimiento que ENAMI atribuye a INCOMIN S. A. en las alegaciones vertidas, se encuentra referido únicamente a las obligaciones que, en el contexto de lo estipulado, exhiben una importancia de menor relieve respecto de otras. Concluyen los sentenciadores:

"Que, resumiendo lo razonado en las consideraciones precedentes -y al margen de la inoportunidad y consiguiente improcedencia de su formulación-- la pretendida defensa de ENAMI, fundada en el incumplimiento parcial de INCOMIN S.A. respecto de las obligaciones que, en el contexto global del contrato, presentan una envergadura menor, no constituía un motivo suficientemente serio que la excusase de satisfacer su compromiso principal y básico para la ejecución del contrato como era aquél de entregar a INCOMIN S.A. la cantidad acordada de mineral en bruto para el procedimiento de lixiviación".[38]

Como se observa, la Corte consideró que conforme las exigencias de la buena fe, el incumplimiento de INCOMIN debía tener una cierta entidad como para justificar la suspensión de la entrega de 30.000 toneladas mensuales de mineral para su tratamiento que pretendía ENAMI; dicha entidad, por decirlo de alguna forma, se mide contra la obligación cuya suspensión se pretende.

En otro fallo, ahora de la Corte de Apelaciones de Temuco, de 11 de septiembre de $2015^{[39]}$, analizó la procedencia de la excepción de incumplimiento contractual del arrendador al entregar el bien raíz con importantes defectos materiales que impedían su uso como complejo hotelero. La Corte tiene por establecer las condiciones que deben concurrir para dar lugar a la excepción. Citando a la profesora Claudia MejíasAlonzo, se lee del fallo que:

"la doctrina suele mencionar: que estemos en presencia de un contrato bilateral; que las obligaciones sean actualmente exigibles; que el acreedor, contra quien se opone la excepción, no haya cumplido con su prestación ni se encuentre llano a hacerlo y, se agrega, por la mayoría de los autores, que el deudor la oponga de buena fe". ${ }^{40]}$

Posteriormente, el tribunal indica que no se actúa de buena fe si el incumplimiento que se pretende denunciar es de menor entidad o poca monta, o si deriva de otro incumplimiento que tenga por causa el hecho del que alega la excepción. De esta manera, si el incumplimiento es irrelevante, no justifica la suspensión del cumplimiento $^{[41]}$.

Conforme a todo lo expuesto, podemos entender que incluso en el caso de que ambas partes no cumplan sus obligaciones (hallándose presente la relación de causalidad o de simultaneidad) o de no mediar proporcionalidad entre las obligaciones o entre los incumplimientos \#el que habilita la procedencia de la excepción y el de la contraparte\# entonces el remedio no debe prosperar.

Se aprecia, de este modo, cómo la buena fe cumple el papel de limitar la procedencia de la excepción de contrato no cumplido en este punto. Si bien este remedio procede ante cualquier incumplimiento, como se ha anotado más arriba ${ }^{[42]}$, necesario es que exista una relación de proporcionalidad entre los 
incumplimientos. Y es, precisamente, esta exigencia la materialización de la buena fe como límite a la excepción de contrato no cumplido. Si el incumplimiento que se aduce como justificación para la propia suspensión es desproporcionado con la propia prestación, la buena fe actuará impidiendo el ejercicio del remedio. Entonces, no se mira a la gravedad del incumplimiento, sino más bien a la relación de aquel con el propio que se suspende. Y esta exigencia halla su fuente en la buena $\mathrm{fe}^{[43]}$.

\section{Sobre los efectos de la excepción de contrato no cumplido sobre el resto de los remedios contractuales}

Al preguntarnos por los efectos de la excepción de contrato no cumplido, nos referimos a las relaciones existentes entre esta y los remedios contractuales frente a los que cuales el excipiens procura defenderse.

Una primera cuestión que es preciso clarificar es que la excepción da al excipiens la facultad para suspender el cumplimiento de su obligación, mientras que la contraparte, es decir, el demandante, no ha hecho lo propio o lo ha hecho imperfectamente. La suspensión, entonces, se traduce en una neutralización de la exigibilidad de la obligación de quien se defiende con la excepción de contrato no cumplido, asemejándose en cuanto al efecto con el caso fortuito.

Con ello, resulta claro que el instituto en estudio altera la procedencia de, por lo menos, dos de los remedios contractuales: la pretensión de cumplimiento específico y la indemnización de perjuicios. Las anteriores, tienen por supuesto que la obligación le sea exigible al deudor y que, no obstante, no cumpla. En Chile no parece cuestionarse que la excepción obstaculiza estos dos medios de tutela del acreedor ${ }^{[44]}$.

En lo que refiere a la acción indemnizatoria, el Código Civil establece explícitamente que la indemnización se debe desde que el deudor se halla en mora. Y, complementando la regla para los contratos sinalagmáticos, el artículo 1552 prescribe que en esta clase de contratos ninguna de las partes está en mora de cumplir mientras el otro contratante no cumpla lo pactado o no esté llano a cumplirlo. Entonces, equién puede discutir que la excepción de contrato no cumplido incide en la procedencia de la indemnización de daños?

En relación con la pretensión de cumplimiento específico, si bien no existen reglas con alcance general en el Código Civil, la misma solución para la indemnización la podemos extraer del principio de la fuerza obligatoria del artículo 1545, conforme el cual la ejecución de la obligación presupone su exigibilidad ${ }^{[45]}$.

\section{Eficacia de la excepción ante el remedio resolutorio}

Sin olvidar que en relación con los efectos de la figura en estudio existe un relevante cuestionamiento por parte del profesor Bruno Caprile ${ }^{[46]}$, nos ocuparemos en analizar su incidencia en la facultad resolutoria del artículo 1489 del Código Civil pues, como se verá, es el que mayores inconvenientes ha reportado para la academia y los tribunales.

Es posible inducir una primera idea con la siguiente pregunta: ¿resulta posible enervar una demanda resolutoria por medio de la excepción de contrato no cumplido?

La opinión tradicional de la doctrina y jurisprudencia local afirma que la excepción de contrato no cumplido enerva la acción resolutoria. Su argumento principal descansa en la regla del artículo 1489 del Código Civil, puesto que las condiciones que integran el supuesto de hecho del remedio resolutorio, conforme con su interpretación, son la existencia de un incumplimiento grave e imputable al deudor, y que quien demande la resolución sea el contratante diligente, es decir, aquel que haya cumplido o esté llano a cumplir su obligación ${ }^{[47]}$. De este modo, la mora integraría no solo los supuestos de hecho de la indemnización y el cumplimiento específico, sino también el de la resolución. ${ }^{[48]}$ La doctrina lee conjuntamente las disposiciones de los artículos 1489 y $1552^{[49]}$. Por ejemplo, la opinión de Alessandri, quien, al criticar 
profusamente una sentencia de la Corte Suprema de 9 de julio de 1931, caratulada "Aravena con Lizarralde, sentencia que dio lugar a la resolución en un caso de incumplimiento recíproco sostiene:

"Esta solución aparece como un medio ideado para mantener la decisión de los jueces sentenciadores que, si estaba reñida
con la ley, se conformaba con la equidad. Como dice el considerando 20 , la cuestión sometida a la casación era determinar si
pudo el demandante, que no cumplió sus obligaciones, impetrar la resolución del contrato frente al demandado que tampoco
dio cumplimiento a las suyas. Esta cuestión, contrario a lo que dice la Corte, está resuelta en forma concreta por el Código
Civil en sus artículos 1489 y 1552 CCCh, ya que éstos, como la misma Corte lo establece en sus considerandos $13^{\circ}$ a 17 ,
sólo confieren la acción resolutoria al contratante que cumplió o que está llano a cumplir el contrato contra el otro que se
niega a hacerlo. Por esto estimo quebrantado el artículo 1489 CCCh. Pues la sentencia recurrida admitió la acción resolutoria
deducida por el contratante que no cumplió su obligación es contra el otro que tampoco habría cumplido las suyas" 50$]$.

Hoy, la doctrina actual del derecho de contratos, sin atender al artículo 1552, excluye la procedencia de la facultad resolutoria para hipótesis de incumplimientos recíprocos. Así, Pizarro Wilson ha afirmado que:

"En mi opinión, el incumplimiento recíproco de las obligaciones impide resolver el contrato no en razón de la excepción prevista en el artículo 1552, sino que, invocando la falta de un elemento de la acción resolutoria, cuál es la calidad de acreedor diligente del demandante. Basta constatar el incumplimiento de sus obligaciones por el demandante para rechazar la demanda de resolución de contrato" ${ }^{51]}$.

Finalmente, los tribunales no sólo en la primera mitad del siglo XIX, sino tambien en algunas sentencias más recientes han fallado admitiendo la excepción de contrato no cumplido y rechazando la demanda del remedio resolutoria por no haberla ejercitado el contratante diligente ${ }^{[52]}$.

En un sentido distinto, Caprile, quien cuestiona la posición clásica, para mostrar sus consecuencias desfavorables formula una serie de interrogantes:

“Si el promitente comprador no puede demandar la resolución del contrato de promesa de compraventa, ¿cómo obtendrá la restitución del anticipo de precio que pagó? En el mismo sentido, si el promitente vendedor anticipó la entrega material del inmueble, ¿cómo lo recupera? (...). Si no procede la acción resolutoria: ¿hasta cuándo quedará en suspenso el contrato? ¿Lo anterior significa que, mientras corren los cinco años hasta que se cumpla el plazo de prescripción de las obligaciones contractuales, el promitente vendedor no podrá transferir el inmueble a un tercero, pues la promesa sigue vigente? Y si lo hace, ¿el tercero adquirente quedará expuesto a una acción de responsabilidad aquiliana que pueda dirigir en su contra el promitente comprador, por haber cooperado o haberse constituido cómplice en la violación de una obligación contractual? En el mismo sentido, ¿significa que, en cualquier momento, cualquiera de las partes puede razonar que ahora el negocio le conviene y, por ende, exigir su cumplimiento, allanándose naturalmente a cumplir sus propias obligaciones?”[53].

Actualmente, la postura dominante es la que estima que en casos de incumplimientos recíprocos -o simultáneos, en nuestra terminología- la excepción de contrato no cumplido no obsta la resolución. Así lo reconoce la sentencia de de la Corte Suprema del 4 de diciembre de 2003. En el caso, el máximo tribunal casa de oficio dicta sentencia de reemplazo, acogiendo la resolución del contrato y rechaza la demanda de indemnización de daños. La sentencia, reconociendo el incumplimiento recíproco de las partes, recalca lo siguiente:

“Que el artículo 1489 del Código Civil envuelve una regla que rige exclusivamente la situación que se produce en los contratos bilaterales cuando una de las partes ha cumplido o está llana a cumplir el contrato y la otra se niega a hacerlo. (...) confirman esta interpretación los fundamentos racionales y de equidad y justicia que inspiran esa disposición que no son otros que presumir que en los contratos bilaterales cada una de las partes consienten en obligarse a condición que la otra se obligue a su vez para con ella, o sea, la reciprocidad de las obligaciones acarrea necesariamente la de las prestaciones. Que, aunque no hay precepto alguno que resuelva la cuestión de si uno de los contratantes que no ha cumplido las obligaciones contraídas puede o no solicitar la resolución de la promesa de venta en contra de la otra parte que tampoco ha dado cumplimiento a las suyas, los jueces están en el deber de juzgarla del modo que más conforme parezca al espíritu general de la legislación y a la equidad natural de acuerdo con lo preceptuado en el No 5 del artículo 170 del Código de Procedimiento Civil. En efecto no parece justo ni equitativo dejar a las partes ligadas por un contrato que ambas no quieren cumplir y que de hecho aparece así ineficaz por voluntad de las mismas. Luego no pugna, por lo tanto, con la índole y naturaleza de los principios jurídicos que informan la acción resolutoria que ella se acoja en este caso, porque la resolución, precisamente el medio que la ley otorga 
para romper un contrato que nació a la vida del derecho, pero que no está llamado a producir sus naturales consecuencias en razón de que las partes se niegan a respetarlo y todavía, porque acogiéndola se llega a la realidad propia de toda resolución, cual es que las cosas puedan restituirse al estado anterior, como si el contrato no hubiese existido, sin embargo no procede la indemnización de perjuicios pedida pues ella requiere de mora y en este caso no podría existir para ninguna de las partes de conformidad con lo dispuesto en el artículo 1552 del citado Código Civil./ 6o. Que la referida conclusión ha sido aceptada por la jurisprudencia (R.D.J. T. 28 sección 1a página 687 y 57, sección 1a, página 274) y corroborada por la doctrina”[54].

Otro fallo del máximo tribunal, del 18 de enero de 2016, que se pronuncia sobre la resolución e indemnizacion de perjuicios por un contrato de prestación de servicios, siguiendo la doctrina de la sentencia de 4 de diciembre de 2003, reconoce un vacío en el artículo 1489 Código Civil -que la parte que pida la resolución no haya cumplido ni éste llana a cumplir con su parte en el contrato-, expresa que:

\footnotetext{
"En efecto, no parece justo ni equitativo dejar a las partes ligadas por un contrato que ambas no quieren cumplir y que de hecho aparece así ineficaz por voluntad de las mismas. Luego no pugna, por lo tanto, con la índole y naturaleza de los principios jurídicos que informan la acción resolutoria que ella se acoja en este caso, porque la resolución es precisamente el medio que la ley otorga para romper un contrato que nació a la vida del derecho, pero que no está llamado a producir sus naturales consecuencias en razón de que las partes se niegan a respetarlo y, todavía, porque acogiéndola se llega a la realidad propia de toda resolución, cual es que las cosas puedan restituirse al estado anterior, como si el contrato no hubiese existido. Sin embargo, en el caso en cuestión no procede la indemnización de perjuicios pedida, pues ella requiere de mora y en este caso no podría existir para ninguna de las partes de conformidad con lo dispuesto en el artículo 1552 del citado Código Civil, que dispone que en los contratos bilaterales ninguna de las partes está en mora dejando de cumplir lo pactado, mientras el otro no lo cumple por su parte o no se allana a cumplirlo, motivo que decidirá a estos sentenciadores a hacer lugar a la acción de resolución del contrato, en los términos que se declarará en la parte resolutiva del fallo" ${ }^{\text {[55] }}$.
}

Lo anterior puede formularse de la siguiente manera: en supuestos de incumplimientos simultáneos, a cada parte le asiste la facultad de suspender el cumplimiento de su obligación y oponer la excepción, la cual producirá la exclusión de la indemnización de daños, mas no de la resolución por incumplimiento, la cual siempre se sujetará a la existencia de un incumplimiento esencial.

De este modo, es posible resaltar que esta solución resulta de vital interés en casos en que alguno de los contratantes incumple -excusada, claro, en el incumplimiento de la otra- hubiera cumplido parcialmente sus obligaciones, como es el caso del primer fallo citado, que, junto con acoger la resolución de un contrato de promesa, da lugar a sus efectos restitutorios.

En síntesis, es posible concluir que para la Corte Suprema el artículo 1489 del Código Civil sólo prevé para un supuesto, aquél en el que una de las partes no cumple y la otra si o está llana a hacerlo. El Código Civil chileno, entonces, no se hace cargo del supuesto en que ambos contratantes incumplan sus obligaciones y, en opinión de la Corte Suprema, debe colmarse de acuerdo con el artículo 170, n. 5 del Código de Procedimiento Civil, aplicando principios de equidad y el espíritu general de la legislación para dar lugar a la acción resolutoria y declarar resuelto el contrato.

Si bien esta solución ha sido acogida, se ha fundado en diversos argumentos. Elgueta-Ortiz, por ejemplo, esgrima una postura que es precisamente la que adopta nuestra Corte Suprema. Para el autor constituye un error no dar lugar a la resolución en caso de incumplimiento recíproco, pues se daría lugar a una exigencia impropia: condicionar la titularidad de la acción resolutoria a haber cumplido las obligaciones propias. Aduce, además, que en este punto el articulo 1489 presenta un vacío. Termina por afirmar que, si las partes no han cumplido, ambas tienen derecho a pedir la resolución del contrato ${ }^{[56]}$.

María Sara Rodríguez-Pinto, comentando la sentencia del 2003, explica que, al demandar la resolución, la actora busca verdaderamente una restitución. De esta forma, el recurso a las fuentes subsidiarias de la equidad y el espíritu general de la legislación representan un instrumento para repeler un caso de enriquecimiento sin causa a costa de los incumplimientos recíprocos ${ }^{[57]}$.

Bruno Caprile, por su parte, acepta la procedencia de la resolución pese a la oposición de la excepción de contrato no cumplido, pero se aleja del razonamiento hecho por la Corte Suprema, fundando su opinión particularmente en que la mora no constituye condición de la resolución, pero sí de la indemnización y, al 
mismo tiempo, que no podemos confundir la mora y la excepción de contrato no cumplido. Cada una con ámbitos de aplicación diferenciados ${ }^{[58]}$.

En conclusión, la opinión dominante es aquella que considera que, en hipótesis de incumplimientos recíprocos, la excepción de contrato no cumplido no impide la resolución del contrato; su procedencia requiere de la existencia de un incumplimiento esencial. Vale decir que ambas partes son titulares eventualmente de la excepción de contrato no cumplido y de la resolución por inejecución.

\section{La excepción de incumplimientos vinculados causalmente y la resolución del contrato}

En lo que nos queda, examinaremos aquellos supuestos en que el incumplimiento de uno de los contratantes se explica por el incumplimiento de su contraparte; o sea, en los casos en que es posible definir una relación de causalidad entre ambos incumplimientos.

En esta hipótesis, cabe preguntarnos: ¿tiene lugar la resolución? Para responder a este cuestionamiento hemos de recordar que el criterio de la causalidad tiene dos sentidos. El primero hace relación con que la parte que incumple provocando que la otra suspenda su cumplimiento, carece de la excepción; y, el segundo, que la parte que suspende su cumplimiento en razón del cumplimiento anterior, sí puede oponerla a su contratante incumplidor.

\section{a) Es procedente la excepción de contrato no cumplido}

En el ya examinado caso de los semirremolques tolva, si bien el comprador sólo opuso la excepción de contrato no cumplido, podría perfectamente haber demandado reconvencionalmente la resolución del contrato de compraventa. Si tal hubiese sido el caso, aplicando el criterio de la causalidad como argumento justificativo del rechazo de la excepción de contrato no cumplido, la resolución no quedaría sujeta a otro límite más que a la calificación de la gravedad o esencialidad del incumplimiento. En este caso lo era, porque las anomalías materiales de los semirremolques eran de tal magnitud que la hacían inhabil para el propósito por la que fueron comprados ${ }^{[59]}$.

Desde luego, la respuesta es patente puesto que, como tuvimos ocasión de explicar, en un caso como este, el vendedor no es titular de la excepción de incumplimiento.

\section{b) El contratante que incumple no es titular de la excepción de contrato no cumplido.}

En este supuesto la causalidad del incumplimiento -que justifica el rechazo de la excepción- plantea ciertas peculiaridades, en el entendido de que la doctrina mayoritaria ha sostenido que el contratante que provoca el incumplimiento de la otra no sólo está privado de la excepción de contrato no cumplido, sino también de la acción de resolución del contrato ${ }^{[60]}$.

Y para ilustrar lo expresado conviene preguntarnos acerca de la posición en que queda el vendedor de los semirremolques tolva defectuosos. Esto, porque, al privarle de la acción resolutoria, se le priva de la restitución de los semirremolques tolvas que, aun siendo muy defectuosos, han de representar algún valor para el vendedor. Consideramos que, al privar al vendedor de la acción resolutoria, estaríamos justificando un enriquecimiento injustificado a favor del comprador, pues él conservaría los camiones sin haber pagado suma 
alguna a título de precio. En tal supuesto, el vendedor no tendría otro medio que la acción in rem verso para obtener la restitución de los semirremolques tolva.

El punto, sin embargo, es que no alcanzamos a divisar cuáles serían las razones que justificarían una solución como esta, más cuando hay acuerdo en orden a que el supuesto de hecho de la resolución se limita solamente a la existencia de un incumplimiento esencial ${ }^{[61]}$.

Todo pareciera indicar que se estaría imponiendo una suerte de sanción al contratante que incumple haciendo procedente la excepción de contrato no cumplido. Habría un reproche a su conducta, todo lo cual resulta bastante ajeno a la actual construcción del derecho de contratos, sin llegar a considerar la ausencia de una norma que prive a este contratante de la acción resolutoria.

En nuestra opinión, prima facie, no habría buenas razones para negar a este contratante la acción de resolución, por el contrario, las habría para reconocerlas. De cualquier modo, la objeción a este postulado es que reconocer la titularidad de la acción resolutoria en este supuesto podría significar dejar abierta una puerta para que los contratantes incumplan y posteriormente soliciten la resolución, obteniendo un provecho de su propio dolo o culpa grave (porque si es el caso, al menos habría actuado con culpa grave). Si se está fuera el caso y se logra acreditar en juicio que el contratante que pide la resolución incumplió con dolo o culpa grave, podríamos adoptar una solución similar a la que se extrae del inciso segundo del artículo 1558 Código Civil chileno, esto es, dejar a un lado el contrato que reconoce la acción resolutoria al contratante afectado por un incumplimiento esencial, privándole así de la acción.

\section{Algunas conclusiones}

De todo lo expuesto, podemos arribar a las ideas que a continuación se expresan:

1. La excepción de contrato no cumplido dota a las partes de la facultad de suspender el cumplimiento de su parte en el contrato y siempre presupone incumplimientos recíprocos, sean simultáneos, sean uno consecuencia de otro.

2. El incumplimiento en que se funda la excepción de contrato no cumplido debe ser de entidad o relevante magnitud o, si se prefiere, proporcional al incumplimiento de quien la opone en juicio.

3. La excepción de contrato no cumplido, en atención a que la exigibilidad de la obligación de quien interpone se ve afectada por el incumplimiento, solo sirve para evitar la pretensión de cumplimiento específico y la indemnización de daños, no a la demanda resolutoria. Esta última sólo requiere de un incumplimiento que pueda calificarse de esencial, grave o resolutorio.

\section{Bibliografía}

Albert Lamarca-Marqués, El hecho del acreedor y la imposibilidad de la prestación, Real Colegio de España (2001).

Alexander Von Ziegle, The right of suspension and stoppage in transit (and notification thereof), 25 The Journal of Law and Commerce, 353-374 (2005).

Alfonso Calvo-Caravaca, Comentario al art. 71, en La Compraventa Internacional de Mercaderías (Luis Díez-Picazo coord., 1998).

Álvaro Pérez-Vives, Teoría general de las obligaciones, Ed. Temis (1953).

Antonio Cabanillas-Sánchez, Las cargas del acreedor en el derecho civil y mercantil (1988).

Arturo Alessandri-Rodríguez, Comentario a una sentencia de la Corte Suprema de 9.07.1931, Revista de Derecho y Jurisprudencia, n. 42 (1931). https://doi.org/10.4067/S0718-68512014000100003

Arturo Alessandri-Rodríguez, De los contratos, Ed. Jurídica de Chile (2009). 
Arturo Alessandri-Rodríguez, Manuel Somarriva-Undurraga, Antonio Vodanovic-Hacklika, Tratado de las obligaciones. Del cumplimiento e incumplimiento de las obligaciones; de la protección de los derechos del acreedor; de la insolvencia y las formas de pago de los deudores insolventes, Ed. Jurídica de Chile (2. ${ }^{\text {a }}$ ed., 2004).

Augusto Elgueta-Anguita, Resolución de contrato y excepción de pago Ed. Jurídica de Chile (1981).

Augusto Elgueta-Ortiz, La resolución y el incumplimiento recíproco (estudio de un caso de interpretación del art. 1489 del código civily de integración de una laguna legal mediante el procedimiento por analogía) (1947). (Memoria de prueba para optar al grado de licenciado en la facultad de ciencias jurídicas y sociales, Universidad de Chile).

Bruno Caprile-Biermann, Algunos problemas ofrecidos por la excepción de contrato no cumplido y, en especial, el de su invocación para atajar la acción resolutoria en el caso de incmplimiento reciproco de los contratantes, Revista de Derecho de la Pontificia Universidad Católica de Valparaíso, n. ${ }^{\circ}$ 39, 53-93 (2012). https://doi.org/10.4067/S0 718-68512012000200002

Bruno Rodri\#guez-Rosado, Resolucio\#n y sinalagma contractual, Ed. Marcial Pons, 100 (2013).

Carlos Chinchilla-Imbett, La excepción de incumplimiento contractual. Estructura, función y límites, Ed. Universidad Externado de Colombia (2018).

Carlos Pizarro-Wilson \& Álvaro Vidal-Olivares, Riesgo del contrato, incumplimiento contractual y remedios. Una relectura para el Derecho Civil chileno, en Lo público y lo privado en el Derecho, Ed. Thomson Reuters (2017).

Carlos Pizarro-Wilson, La excepción por incumplimiento contractual en el Derecho civil chileno, en II Cuadernos de Análisis Jurídico, Ed. Universidad Diego Portales, 324 (2005).

Claudia Mejías-Alonzo, La excepción de contrato no cumplido y su consagración en el Código Civil Chileno, 40 Revista Chilena de Derecho, n. ${ }^{\circ}$ 2, 389-412 (2013). https://doi.org/10.4067/S0718-34372013000200002

Claudia Mejías-Alonzo, La excepción de contrato no cumplido, un análisis de su aplicación en la jurisprudencia nacional reciente y en la doctrina, 21 Revista de Derecho de la Universidad Católica del Norte, n. ${ }^{\circ}$ 1, 111-156 (2014). ht tps://doi.org/10.4067/S0718-97532014000100004

Código Civil colombiano [CCC]. Ley 57 de 1887. Arts. 1609 y ss. 15 de abril de 1887 (Colombia).

Código Civil de Chile [CCCh]. Ley de 14 de diciembre de 1855. Art. 1552. 1 de enero de 1857 (Chile).

Código Civil Francés [CCFr]. Ley del 21 de marzo de 1804. Arts. 1219. 21 de marzo de 1804 (Francia).

Código Civil y Comercial Unificado de la Nación [CCCUN]. Ley 26994 de 2014. Arts. 1031. 7 de octubre de 2014

(Argentina).

Código de Procedimiento Civil de la República de Chile. Ley 1552 del 28 de agosto de 1902. Artículo 170 (Chile)

Comisión de Derecho Europeo de los Contratos, Commission on European Contract Law, Comment $B$ (iii) of the article 8:101 PECL, en Principles of European Contract Law (Ole Lando ed., 2000).

Corte Suprema de Chile. Rol n. ${ }^{\circ}$ 3981-2001. "Mariela Renee Luza Tapia con Sociedad Constructora Inmobiliaria Delfos S.A., 3 de septiembre de 2002.

Corte de Apelaciones de La Serena. Rol n. ${ }^{\circ}$ 1203/2011. "Alcar con U. Católica del Norte”, 19 de diciembre de 2011.

Corte de Apelaciones de La Serena. Rol n. ${ }^{\circ} 39-2012$. “Pirodais con Serena”, 31 de julio de 2012.

Corte de apelaciones de San Miguel. Rol n. 486-2012. "Moyano Sepúlveda Kathia Pamela con González Pereira Eduardo Gastón”, 7 de septiembre de 2012.

Corte de Apelaciones de Santiago. n. ${ }^{\circ}$ 1744-2008. “Parra Riffo, Héctor con Rafide Morales, Juan”, 19 de agosto de 2009. Corte de Apelaciones de Santiago. Rol n. . 6212-2015. "Javier Medina Casanova con Instituto de Normalización Previsional", 18 de enero de 2016.

Corte de Apelaciones de Temuco. Rol n. ${ }^{\circ}$ 758-2014, "Ademar Teodomiro Suárez con Christel y Nicolás Mazet Limitada", 11 de septiembre de 2015.

Corte Suprema de Chile. Rol n. ${ }^{\circ}$ 1594-2001. "Incomin con Enami”, 31 de marzo de 2003.

Corte Suprema de Chile. Rol n. ${ }^{\circ}$ 3789-2009. “Fuentes Rodríguez, José Belisario con Canteras Lonco S.A.”, 24 de marzo de 2011. 
Corte Suprema de Chile. Rol n. ${ }^{\circ}$ 3325-20. "Zorín S.A con Compañía Siderúrgica Huachipato S.A.", 31 de octubre de 2012.

Cristián Aedo-Barrena, Cargas o deberes en la posición contractual del acreedor con especial referencia a su mora de recibir, en Colección de estudios de Derecho civil en homenaje a la profesora Inés Pardo de Carvallo (Alejandro Guzmán Brito ed., 2008).

Enrique Alcalde-Rodríguez, Acción resolutoria y excepción de contrato no cumplido, algunas precisiones fundamentales respecto del ámbito de aplicación, 8 Revista Actualidad Jurídica, 69-93 (2003).

Fabricio Mantilla-Espinosa, La excepción de inejecución, en Los contratos en el derecho privado (Fabricio MantillaEspinosa \& Fernando Ternera-Barrios eds., 2007).

Fernando Fueyo-Laneri, Cumplimiento e incumplimiento de las obligaciones, Ed. Jurídica de Chile (3. a edición actualizada por Gonzalo Figueroa-Yañez, 2004).

Guillermo Ospina-Fernández \& Eduardo Ospina-Acosta, Teoría general del contrato y del negocio jurídico, Ed. Temis (2016).

I Fernando Hinestrosa, Tratado de las obligaciones. Concepto, estructura y vicisitudes, Ed. Universidad del Externado de Colombia (2002).

I René Abeliuk-Manasevich, Las obligaciones, Ed. Jurídica de Chile (2009).

II Fernando Hinestrosa, Tratado de las obligaciones II. De las fuentes de las obligaciones: el negocio jurídico, Ed. Universidad del Externado de Colombia (2015).

II Luis Di\#ez-Picazo, Fundamentos de derecho civil patrimonial, Ed. Civitas (1996).

II Luis Díez-Picazo, Fundamentos de Derecho Civil Patrimonial, Ed. Civitas, 693 (1996).

II René Abeliuk-Manasevich, Las obligaciones, Ed. Thomson Reuters (6.a ed., 2014).

Ingeborg Schwenzer, Schlectriem \& Schwnzer: Commentary on the UN Convention on the International Sales of Goods, Ed. Oxford University Press (2016).

International Institute for the Unification of Private Law (UNIDROIT), Principios de Unidroit (2016). http://uni lex.info

Íñigo De La Maza-Gazmuri \& Álvaro Vidal-Olivares, El contenido de los PDLC, en Los Principios Latinoamericanos de Derecho de Contratos (Î́ñigo De La Maza-Gazmuri, Carlos Pizarro-Wilson \& Álvaro Vidal-Olivares eds., 2017).

Iñigo De La Maza-Gazmuri, Carlos Pizarro-Wilson, Álvaro Vidal-Olivares, Los Principios Latinoamericanos de Derecho de los Contratos (2017).

Jean Carbonnier, Droit Civil, Ed. Presse Universitaires de France, 2245-2246 (2004).

Jorge Cubides-Camacho, Obligaciones, Ed. Ibañez (2017).

Jorge López-Santa María, Los Contratos. Parte General, Ed. Abeledo Perrot (2010).

Jorge Oviedo-Albán, El contrato de promesa en el derecho privado. Ed. Depalma, Pontificia Universidad Javeriana \& Ibañez (2010).

Juan Contardo-González, La resolución por anticipación opor incumplimiento previsible. Intento de construcción a partir de los artículos 1826 del Código Civil y 147 del Código de Comercio, en Estudios de Derecho Civil VIII (Carmen Domínguez-Hidalgo ed., 2013).

Juan Contardo-González, Obligaciones y responsabilidad civil, en Revista Chilena de Derecho Privado, n. ${ }^{\circ}$ 23, 341-350 (2014). http://dx.doi.org/10.4067/S0718-80722014000200011

Juan Contardo-González, Recensión Rodríguez- Rosado, Bruno, Resolución y sinalagma contractual, en Revista Chilena de Derecho Privado, n. ${ }^{\circ} 24,277-286$ (2015). http://dx.doi.org/10.4067/S0718-80722015000100014

Juzgado Civil de Talca. Rol n. 59.502 "Centro Médico Dental Santa Marta con Verdugo", 4 de diciembre de 2003.

Lilian San Martín-Neira, Sobre la naturaleza jurídica de la 'cooperación' del acreedor al cumplimiento de la obligación, Revista de Derecho Privado n. $21,273-325$ (2011).

Luis Claro-Solar, Explicaciones de derecho civil chileno y comparado. De las obligaciones, Ed. Jurídica de Chile (1978). 
María Sara Rodríguez-Pinto, El principio 'Nadie debe hacerse más rico en detrimento de otro' (D.12, 6, 14) en la resolución de un contrato de promesa por incumplimientos reciprocos: una tendencia jurisprudencial chilena, en Estudios de Derecho Civil II (2006).

Mario Clemente-Meoro, La facultad de resolver los contratos por incumplimiento, Ed. Tirant lo Blanch (1999).

Nieves Fenoy-Picón, La modernización del régimen del incumplimiento del contrato: Propuestas de la Comisión General de Codificación. Parte primera: Aspectos generales. El incumplimiento, LXIII Anuario de Derecho Civil, n. ${ }^{\circ}$, 47-136 (2010).

Organización de las Naciones Unidas, Convención de las Naciones Unidas sobre los Contratos de Compraventa Internacional de Mercaderías, 11 de abril de 1980. https://www.uncitral.org/pdf/spanish/texts/sales/cisg/V10 57000-CISG-s.pdf

Pablo Rodríguez-Grez, Sobre la excepción del contrato no cumplido, 5 Revista de Actualidad Jurídica, n. ${ }^{\circ}$ 9, 121-130 (2004).

Pamela Prado-López, La colaboración del acreedor en los contratos civiles, Ed. Thomson Reuters (2015).

Pamela Prado-López, La inobservancia al deber de colaboración del acreedor en el derecho chileno: un caso de incumplimiento contractual, 29 Revista de Derecho (Valdivia), n. ${ }^{\circ}$ 2, 59-83 (2016). http://dx.doi.org/10.4067/ S0718-09502016000200003

Principios Europeos de Derecho de Contratos, PECL (2000). http://campus.usal.es/ derinfo/Material/LegOblCon tr/PECL\%20I+II.pdf

Rodrigo Barcia-Lehmann, Lecciones de Derecho Civil chileno I. Del acto jurídico, Ed. Jurídica de Chile (2010).

Sebastián Bozzo-Hauri, La "excepción de contrato no cumplido adecuada o regularmente" y su régimen en el derecho civil español, Revista de Derecho de la Pontificia Universidad Católica de Valparaíso, n. . 42, 83-119 (2014). https:// doi.org/10.4067/S0718-68512014000100003

Stefan Vogenauer, Commentary on UNIDROIT Principles of International Commercial Contracts (PICC), Ed. Oxford University Press (2015).

Tarek Yusari, Incumplimiento recíproco y remedios contractuales Ed. Thomson Reuters (2012).

Víctor Vial-Del Río, Teoría general del acto jurídico, Ed. Jurídica de Chile (2011).

\section{Notas}

* Artículo de investigación.

[1] Una mirada al artículo 1131 del Código Civil y Comercial argentino, muestra que se reconoce al acreedor la facultad de suspender el cumplimiento de su propia prestación y que dicha facultad puede ejercitarse por vía de acción o de excepción, al prescribir que: "En los contratos bilaterales, cuando las partes deben cumplir simultáneamente, una de ellas puede suspender el cumplimiento de la prestación, hasta que la otra cumpla u ofrezca cumplir. La suspensión puede ser deducida judicialmente como acción o como excepción. Si la prestación es a favor de varios interesados, puede suspenderse la parte debida a cada uno hasta la ejecución completa de la contraprestación". Código Civil y Comercial Unificado de la Nación [CCCUN]. Ley 26994 de 2014. Art. 1131.7 de octubre de 2014 (Argentina).

[2] Luis Claro-Solar, Explicaciones de derecho civil chileno y comparado. De las obligaciones, Ed. Jurídica de Chile, 768 (1978). En Colombia, la doctrina también da el asiento normativo con la norma del artículo 1609 del Código Civil de disponer sobre la ejecución simultánea de los contratos bilaterales. Cfr. entre otros: Jorge Cubides-Camacho, Obligaciones, Ed. Ibañez, 117 (2017). Guillermo Ospina-Fernández \& Eduardo Ospina-Acosta, Teoría general del contrato y del negocio jurídico, Ed. Temis, 542 y 576 (2016). Álvaro Pérez-Vives, Teoría general de las obligaciones, Ed. Temis, 286 (1953). Haciendo alusión a sentencias de la Corte Suprema de Justicia de Colombia que han reconocido la potestad para una parte de no ejecutar su obligación mientras el otro no ejecute la suya, véase: Fabricio Mantilla-Espinosa, La excepción de inejecución, en Los contratos en el derecho privado, 276 (Fabricio Mantilla-Espinosa \& Fernando Ternera-Barrios eds., 2007). Por otra parte, y afirmando que el artículo 1609 del Código Civil colombiano no consagra la excepción de contrato no cumplido, véase Jorge Oviedo-Albán, El contrato de promesa en el derecho privado. Ed. Depalma, Pontificia Universidad Javeriana \& Ibañez, 105-110 (2010). 
[3] En la doctrina colombiana, al calificar a la excepción de contrato no cumplido como remedio del acreedor, al que se le atribuye la función de servir de mecanismo de gestión de la relación contractual, Chinchilla afirma que la excepción de contrato no cumplido consiste en un remedio por medio del cual los contratantes defienden sus propios intereses, de tal manera que su ubicación dentro de los remedios contractuales no de tipo "destructivo" sino "suspensivo", permite entender su función y efectos frente al incumplimiento. Carlos Chinchilla-Imbett, La excepción de incumplimiento contractual. Estructura, función y límites, Ed. Universidad Externado de Colombia, 288 (2018).

[4] Rodrigo Barcia-Lehmann, Lecciones de Derecho Civil chileno I. Del acto jurídico, Ed. Jurídica de Chile, 98 (2010); Víctor Vial-Del Río, Teoría general del acto jurídico, Ed. Jurídica de Chile, 190 (2011).

[5] La triada de los efectos particulares se constituye, además, por la facultad resolutoria o resolución por inejecución (condición resolutoria tácita), y la teoría de los riesgos; I René Abeliuk-Manasevich, Las obligaciones, Ed. Jurídica de Chile, 75 (2009); Arturo Alessandri-Rodríguez, De los contratos, Ed. Jurídica de Chile, 21 (2009).

[6] En este sentido: Carlos Pizarro-Wilson \& Álvaro Vidal-Olivares, Riesgo del contrato, incumplimiento contractual y remedios. Una relectura para el Derecho Civil chileno, en Lo público y lo privado en el Derecho, Ed. Thomson Reuters, 615-640 (2017); Íñigo De La Maza-Gazmuri \& Álvaro Vidal-Olivares, El contenido de los PDLC, en Los Principios Latinoamericanos de Derecho de Contratos, 53 (Íñigo De La Maza-Gazmuri, Carlos Pizarro-Wilson \& Álvaro Vidal-Olivares eds., 2017).

[7] Jorge López-Santa María, Los Contratos. Parte General, Ed. Abeledo Perrot, 74 (2010).

[8] Íd., párr. 91; II Luis Díez-Picazo, Fundamentos de Derecho Civil Patrimonial, Ed. Civitas, 693 (1996).

[9] Claudia Mejías-Alonzo, La excepción de contrato no cumplido y su consagración en el Código Civil Chileno, 40 Revista Chilena de Derecho, n. ${ }^{\circ}$ 2, 406 (2013).

[10] Juan Contardo-González, Recensión Rodríguez-Rosado, Bruno, Resolución y sinalagma contractual, en Revista Chilena de Derecho Privado, n. ${ }^{\circ}$ 24, 277-286 (2015); Juan Contardo-González, Obligaciones y responsabilidad civil, Revista Chilena de Derecho Privado, n. 23,346 (2014).

[11] Organización de las Naciones Unidas, Convención de las Naciones Unidas sobre los Contratos de Compraventa Internacional de Mercaderías, 11 de abril de 1980.

[12] Señala la norma: "1) la facultad que asiste a ambas partes a diferir el cumplimiento de sus obligaciones si, después de la celebración del contrato, resulta manifiesto que la otra parte no cumplirá una parte sustancial de sus obligaciones (...)”. En este punto, véase Alfonso Calvo-Caravaca, Comentarioal art. 71, en La Compraventa Internacional de Mercaderías, $560-566$ (Luis Díez-Picazo coord., 1998); Alexander Von Ziegle, The right of suspension and stoppage in transit (and notification thereof), 25 The Journal of Law and Commerce, 353-374 (2005); Ingeborg Schwenzer, Schlectriem \& Schwnzer: Commentary on the UN Convention on the International Sales of Goods, Ed. Oxford University Press, 179-188 (2016).

[13] Indica el texto que procederá la suspensión: “(1) Cuando las partes han de cumplir simultáneamente, cada parte puede suspender el cumplimiento de su prestación hasta que la otra ofrezca su prestación; (2) Cuando las partes han de cumplir de modo sucesivo, la parte que ha de cumplir después puede suspender su cumplimiento hasta que la parte que ha de hacerlo primero haya cumplido". International Institute for the Unification of Private Law (UNIDROIT), Principios de Unidroit (2016). Se agrega que las condiciones de procedencia que se observan en el citado artículo de los PICC son: incumplimiento, falta de aviso que justifique tal incumplimiento, y reciprocidad de la obligación incumplida por la debida de la contraparte; Stefan Vogenauer, Commentary on UNIDROIT Principles of International Commercial Contracts (PICC), Ed. Oxford University Press, 837-844 (2015).

[14] En el texto de los PLDC, se lee: "Cada parte puede negarse a ejecutar el contrato si la otra no lo ejecuta, a menos que por su naturaleza o por acuerdo de las partes el cumplimiento de una deba anteceder al de la otra”. Véase para el efecto: Iñigo De La MazaGazmuri, Carlos Pizarro-Wilson, Álvaro Vidal-Olivares, Los Principios Latinoamericanos de Derecho de los Contratos, 27-29 (2017). Señala el artículo 91 de los PLDC: "En caso de incumplimiento, el acreedor puede ejercer, a su elección y según proceda, alguno de los siguientes medios de tutela: Cumplimiento específico; Reducción del precio; Resolución del contrato; Suspensión del cumplimiento e Indemnización de perjuicios. La indemnización de perjuicios puede ejercerse de manera autónoma, o en conjunto con los demás medios de tutela”.

[15] International Institute for the Unification of Private Law (UNIDROIT), Principios de Unidroit (2016). Este artículo debe ser leído en conjunto con el artículo 6.1.4 (Orden de cumplimiento). Este artículo se ocupa de los remedios y corresponde a lo que el derecho civil denomina exceptionon adimpleti contractus. 
[16] Código Civil y Comercial Unificado de la Nación [CCCUN]. Ley 26994 de 2014. Arts. 1031. 7 de octubre de 2014 (Argentina).

[17] Une partie peut refuser d'exécuter son obligation, alors même que celle-ci est exigible, si l'autre n'exécute pas la sienne et si cette inexécution est suffisamment grave". Código Civil Francés [CCFr]. Ley del 21 de marzo de 1804. Arts. 1219. 21 de marzo de 1804 (Francia). Versión original disponible [en línea]: http://codes.droit.org/CodV3/civil.pdf.

[18] Sobre la posibilidad de extender la excepción a otras situaciones ver Bruno Caprile-Biermann, Algunos problemas ofr ecidos por la excepción de contrato no cumplido y, en especial, el de su invocación para atajar la acción resolutoria en el caso de incumplimiento recíproco de los contratantes, Revista de Derecho de la Pontificia Universidad Católica de Valparaíso, n. ${ }^{\circ}$ 39, 53-93 (2012).

[19] Salvo, por supuesto, que se acepte que procede frente a incumplimientos anticipados. Ver Claudia Mejías-Alonzo, $L a$ excepción de contrato no cumplido, un análisis de su aplicación en la jurisprudencia nacional reciente y en la doctrina, 21 Revista de Derecho de la Universidad Católica del Norte, n. ${ }^{\circ}$ 1, 111-122 (2014); Juan Contardo-González, La resolución por anticipación o por incumplimiento previsible. Intento de construcción a partir de los artículos 1826 del Código Civil y 147 del Código de Comercio, en Estudios de Derecho Civil VIII (Carmen Domínguez-Hidalgo ed., 2013).

[20] Claudia Mejías-Alonzo, La excepción, un análisis de su aplicación en la jurisprudencia nacional reciente, op. cit., 136.

[21] Tarek Yusari, Incumplimiento recíproco y remedios contractuales Ed. Thomson Reuters (2012); Mario ClementeMeoro, La facultad de resolver los contratos por incumplimiento, Ed. Tirant lo Blanch, 179 (1999).

[22] Comisión de Derecho Europeo de los Contratos, Principios Europeos de Derecho de Contratos, PECL (2000).

[23] La misma regla se encuentra en los artículos 7.1.2 de los PCCI y 8:101 (3) de los PECL, entre otros.

[24] Íñigo De La Maza-Gazmuri, Álvaro Vidal-Olivares, op. cit., 53-54.

[25] En Chile el deber de colaboración del acreedor ha sido calificado como una genuina obligación, así: Pamela Prado-López, La colaboración del acreedor en los contratos civiles, Ed. Thomson Reuters (2015); Pamela Prado-López, La inobservancia al deber de colaboración del acreedor en el derecho chileno: un caso de incumplimiento contractual, 29 Revista de Derecho (Valdivia), n. ${ }^{\circ}$,

59-83 (2016); o como un deber de conducta cuya infracción acarrea la obligación de indemnizar, Lilian San Martín-Neira, Sobre la naturaleza jurídica de la 'cooperación' del acreedor al cumplimiento de la obligación, Revista de Derecho Privado, n. ${ }^{\circ} 21,273-325$ (2011); o como una carga contractual impuesta por el contrato o la buena fe objetiva del artículo 1546 del Código Civil, Cristián Aedo-Barrena, Cargas o deberes en la posición contractual del acreedor con especial referencia a su mora de recibir, en Colección de estudios de Derecho civil en homenaje a la profesora Inés Pardo de Carvallo, 281-303 (Alejandro Guzmán Brito ed., 2008). En España, Nieves Fenoy-Picón, La modernización del régimen del incumplimiento del contrato: Propuestas de la Comisión General de

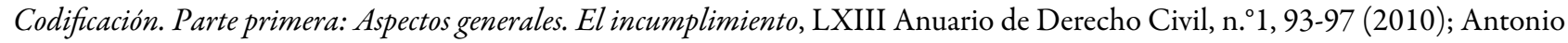
Cabanillas-Sánchez, Las cargas del acreedor en el derecho civil y mercantil, 91 (1988); Albert Lamarca-Marqués, El hecho del acreedor y la imposibilidad de la prestación, Real Colegio de España, 53 (2001); I Fernando Hinestrosa, Tratado de las obligaciones. Concepto, estructura y vicisitudes, Ed. Universidad del Externado de Colombia, 541 (2002). Finalmente, con referencia a los PECL, la Commission on European Contract Law, Comment B (iii) of the article 8:101 PECL, en Principles of European Contract Law, 361 (Ole Lando ed., 2000).

[26] Corte Suprema de Chile. Rol n. ${ }^{\circ}$ 3325-20. "Zorín S.A con Compañía Siderúrgica Huachipato S.A.", 31 de octubre de 2012.

[27] Corte Suprema de Chile. Rol n. ${ }^{\circ}$ 3789-2009. "Fuentes Rodríguez, José Belisario con Canteras Lonco S.A.", 24 de marzo de 2011.

[28] Se lee textualmente del fallo: "Que, en el caso sublite, se cumplen las exigencias requeridas para aplicar el artículo 1552 del Código Civil, porque se trata de obligaciones recíprocas exigibles que constan en un mismo vínculo contractual, concurre buena fe de parte de quien alega la excepción de contrato no cumplido y son faltas o infracciones que emanan del contrato a favor de quien alega la citada infracción. Que, fundada en principios de equidad, buena fe y en la teoría de la causa, la inejecución atribuida al acreedor demandante en el caso sublite incide en una obligación relevante, de real trascendencia en el contrato cuyo incumplimiento en lo concerniente a las especificaciones técnicas convenidas llegaron al extremo que las tolvas objeto del contrato resultaron ulteriormente inservibles para los fines que le son propios". 
[29] Juzgado Civil de Talca. Rol n. ${ }^{\circ} 59.502$ "Centro Médico Dental Santa Marta con Verdugo", 4 de diciembre de 2003. Decimos con cierta distancia porque, como apunta correctamente Tarek Yusari, op. cit., 26. Los hechos del caso muestran que puede establecerse una relación causal entre ambos incumplimientos.

[30] Clemente-Meoro nos muestra un caso de incumplimientos simultáneos y que trata -aunque, con el fin de simplificarlo, con algunas modificaciones- de un contrato por el cual una parte se obliga a pagar el precio y la otra a suscribir la correspondiente escritura de compraventa. Ambas incumplen, ni la una paga el precio, ni la otra suscribe la escritura. Ambas obligaciones se entienden exigibles al mismo tiempo y se producen incumplimientos recíprocos simultáneos; Mario Clemente-Meoro, op. cit., 179; Bruno Caprile-Biermann, op. cit., 77-79.

[31] Código Civil de Chile [CCCh]. Ley de 14 de diciembre de 1855. Art. 1552. 1 de enero de 1857 (Chile).

[32] Claudia Mejías-Alonzo, La excepción, un análisis de su aplicación en la jurisprudencia nacional reciente, op. cit., 123-131.

[33] Fernando Fueyo-Laneri, Cumplimiento e incumplimiento de las obligaciones, Ed. Jurídica de Chile, 241 (3. ${ }^{a}$ edición actualizada por Gonzalo Figueroa-Yañez, 2004); Bruno Caprile-Biermann, op. cit., 58-59.

[34] Ver ejemplos en Claudia Mejías-Alonzo, La excepción, un análisis de su aplicación en la jurisprudencia nacional reciente, op. cit., 123-131.

[35] Corte de apelaciones de San Miguel. Rol n. 486-2012. "Moyano Sepúlveda Kathia Pamela con González Pereira Eduardo Gastón", 7 de septiembre de 2012; se lee de la sentencia: “...esta excepción universalmente conocida como exceptionon adimpleti contractus, institución característica de los contratos bilaterales o sinalagmáticos, cuya fundamentación radica en la teoría de la causa y el principio de la buena fe que debe presidir la ejecución de los contratos".

[36] Claudia Mejías-Alonzo, La excepción, un análisis de su aplicación en la jurisprudencia nacional reciente, op. cit., 127. Una idea que ya aparece en Luis Claro-Solar, Explicaciones de derecho civil chileno y comparado. De las obligaciones, Ed. Jurídica de Chile, 694 (1978). En la doctrina colombiana, también Chinchilla-Imbett advierte que "La buena fe implicaría realizar una valoración del incumplimiento 'legitimado' del excipiens y del incumplimiento 'legitimante' de la contraparte con relación al contrato". Chinchilla-Imbett, op. cit., 369.

[37] Igualmente, simpatizamos con la idea de Sebastián Bozzo-Hauri, La "excepción de contrato no cumplido adecuada o regularmente" y su régimen en el derecho civil español, Revista de Derecho de la Pontificia Universidad Católica de Valparaíso, n. ${ }^{\circ}$ 42, 105 (2014), según la cual un cumplimiento defectuoso que sea de fácil subsanación no debería, al menos en principio, justificar la excepción de contrato no cumplido. Por su parte, Chinchilla considera que el requisito de la gravedad del incumplimiento de la contraparte para el ejercicio de la excepción de incumplimiento conforme de buena fe debe ser leído como un incumplimiento serio, pero no igualable al que se exige para la resolución por incumplimiento contractual, pues de lo contrario afirma el autor-, se desconocería la funcionalidad conservativa de esta institución. Carlos Chinchilla-Imbett, op. cit., 383-390. También, y fundado en la opinión de la jurisprudencia colombiana sobre el tema, Hinestrosa señala que la negativa a cumplir debe estar fundada en motivos serios para hacerlo. II Fernando Hinestrosa, Tratado de las obligaciones II. De las fuentes de las obligaciones: el negocio jurídico, Ed. Universidad del Externado de Colombia, 935 (2015).

[38] Corte Suprema de Chile. Rol n. ${ }^{\circ}$ 1594-2001. “Incomin con Enami”, 31 de marzo de 2003. Señala la sentencia: “(...) es preciso recordar que constituyen hechos de la causa que, como tales, han quedado establecidos en la sentencia recurrida- que, en lo concerniente al cumplimiento de las obligaciones que le imponía el contrato de maquila, ENAMI no satisfizo aquélla consistente en suministrar 30.000 toneladas mensuales de mineral para su tratamiento por parte de INCOMIN S.A.; y ésta cumplió con su obligación de someter al procedimiento de lixiviación el material en bruto que le entregaba ENAMI, construyendo una planta para realizar ese tratamiento, pero incurrió, a su vez, en otra clase de incumplimientos de obligaciones reguladas en el contrato, al haber devuelto productos con exceso de humedad y con menor cantidad de ley de cobre, de acuerdo a la regulación estipulada sobre la materia; por haber incurrido en retrasos al devolver los productos; y por adeudar ciertas prestaciones a ENAMI, a causa de la utilización de un cargador frontal de propiedad de ésta. (...) según aparece de los antecedentes de la sentencia recurrida, establecidos en ella como hechos de la causa, el contrato de maquila celebrado entre ENAMI e INCOMIN S. A. impuso a éstas, obligaciones de diversa índole y trascendencia, siendo las principales: para ENAMI, la de entregar a INCOMIN S .A. 30.000 toneladas de cobre en bruto para su procesamiento en la Cancha del Salar del Carmen y para INCOMIN S. A., la de someter esos minerales a un tratamiento de lixiviación e instalar una planta para realizar dicho procedimiento".

[39] Corte de Apelaciones de Temuco. Rol n. ${ }^{\circ}$ 758-2014, "Ademar Teodomiro Suárez con Christel y Nicolás Mazet Limitada", 11 de septiembre de 2015. 
[40] Claudia Mejías-Alonzo, La excepción de contrato no cumplido, un análisis de su aplicación en la jurisprudencia nacional reciente, op. cit., 113.

[41] “(...) la buena fe desaparece, en primer lugar, si el incumplimiento del acreedor es de pequeña monta, es decir, irrelevante o no presenta conexión con las obligaciones que deben ser cumplidas por el deudor. En segundo lugar, si dicho incumplimiento es consecuencia del incumplimiento en que previamente ha incurrido el deudor (...) se debe hacer presente que el incumplimiento en que ha incurrido en arrendador demandante no puede calificarse de irrelevante y tiene directa relación con el incumplimiento que se reprocha al arrendatario demandado. Por otra parte, el deudor, esto es, el arrendatario demandado, no ha incurrido previamente en el incumplimiento, desde que entregó la renta de arrendamiento correspondiente al primer año completo, y las reparaciones para superar los problemas que presentaba el inmueble se iniciaron tan solo tres meses después de suscrito el respectivo contrato" Corte de Apelaciones de Temuco. Rol n. ${ }^{\circ}$ 758-2014, "Ademar Teodomiro Suárez con Christel y Nicolás Mazet Limitada”, 11 de septiembre de 2015. (Considerando decimotercero).

[42] Claudia Mejías-Alonzo, La excepción, un análisis de su aplicación en la jurisprudencia nacional reciente, op. cit., 127.

[43] Por la doctrina española, Bruno Rodri\#guez-Rosado, Resolucio\#n y sinalagma contractual, Ed. Marcial Pons, 100 (2013). En el caso de la doctrina francesa, Jean Carbonnier, Droit Civil, Ed. Presse Universitaires de France, 2245-2246 (2004).

[44] Bruno Caprile-Biermann, op. cit., 79-90.

[45] Una de las condiciones para la ejecución de una obligación es que ella sea actualmente exigible (artículo 437 CPC). Además, hemos de considerar la disposición del inciso $3^{\circ}$ del artículo 1826 , conforme con el cual la procedencia de la acción de cumplimiento de la obligación de entrega requiere que el comprador haya pagado o esté llano a pagar el precio del contrato. En contra: Enrique Alcalde-Rodríguez, Acción resolutoria y excepción de contrato no cumplido, algunas precisiones fundamentales respecto del ámbito de aplicación, 8 Revista Actualidad Jurídica, 69-93 (2003). Para el autor la excepción de contrato no cumplido sólo repele a la acción indemnizatoria, no así a la acción de cumplimiento, ni la de resolución.

[46] Bruno Caprile-Biermann, op. cit., 53-93.

[47] Arturo Alessandri-Rodríguez, Manuel Somarriva-Undurraga, Antonio Vodanovic-Hacklika, Tratado de las obligaciones. Del cumplimiento e incumplimiento de las obligaciones; de la protección de los derechos del acreedor; de la insolvencia y las formas de pago de los deudores insolventes, Ed. Jurídica de Chile, 295 (2.a ed., 2004); II René Abeliuk-Manasevich, Las obligaciones, Ed. Thomson Reuters, 941 (6a ed., 2014); Pablo Rodríguez-Grez, Sobre la excepción del contrato no cumplido, 5 Revista de Actualidad Jurídica, n. ${ }^{\circ}$ 9, 125 y ss. (2004); Carlos Pizarro-Wilson, La excepción por incumplimiento contractual en el Derecho civil chileno, en II Cuadernos de Análisis Jurídico, Ed. Universidad Diego Portales, 324 (2005).

[48] Por todos: Pablo Rodríguez-Grez, op. cit., 125-127. .

[49] "Si se aplican estos postulados, la derivación lógica es que, en caso de incumplimiento recíproco, cualquiera de los contratantes podrá oponer la excepción de inejecución y, de esa forma, paralizar las acciones de su contraparte. En el lenguaje tradicional, 'la mora purgaría la mora' o, si se quiere, 'incumplo porque incumples”'. Bruno Caprile-Biermann, op. cit., 65.

[50] Arturo Alessandri-Rodríguez, Comentario a una sentencia de la Corte Suprema de 9.07.1931, Revista de Derecho y Jurisprudencia, n. ${ }^{\circ}$ 42, 689 y 693 (1931). En el mismo sentido, Rodríguez Grez ha afirmado: "La referida conclusión no nos parece acertada, por una cuestión fundamental: la mora es condición de exigibilidad de una obligación para todos los efectos relacionados con la interposición de acciones, así\# sea de cumplimiento, resolución o indemnización (...). Si, como nosotros sostenemos, la mora es presupuesto de la exigibilidad de las obligaciones nacidas de los contratos bilaterales, estando pendiente el cumplimiento de la obligación correlativa que nace del contrato bilateral, queda suspendida la ejecución de dichas obligaciones y, como es obvio, no podrá\# demandarse ni la resolución ni el cumplimiento forzoso. La mora, como se dijo, es un estado jurídico especial según el cual el retardo en el cumplimiento de la obligación es imputable al deudor. A partir de ese instante puede este último ser sujeto de la acción de cumplimiento forzoso o resolución y, en ambos casos, con más una indemnización de perjuicios, derecho que, tratándose de obligaciones pendientes, deberá\# ir unido a otra cosa (ejecución forzosa o resolución)"; Pablo Rodríguez-Grez, Sobre la excepción del contrato no cumplido, 5 Revista de Actualidad Jurídica, n. ${ }^{\circ}$ 9, 121-130 (2004).

[51] Carlos Pizarro-Wilson, op. cit., 332.

[52] Corte Suprema de Chile. Rol n. ${ }^{\circ}$ 3981-2001. "Mariela Renee Luza Tapia con Sociedad Constructora Inmobiliaria Delfos S.A., 3 de septiembre de 2002; Corte de Apelaciones de La Serena. Rol n. ${ }^{\circ}$ 1203/2011 “Alcar con U. Católica del Norte”, 19 de diciembre de 2011. (2011); Corte de Apelaciones de La Serena. Rol n. ${ }^{\circ}$ 39-2012. "Pirodais con Serena”, 31 de julio de 2012. 
[53] Bruno Caprile-Biermann, op. cit., 68-72.

[54] Juzgado Civil de Talca. Rol n. ${ }^{\circ} 59.502$ “Centro Médico Dental Santa Marta con Verdugo", 4 de diciembre de 2003. En el mismo sentido, véase Corte de Apelaciones de Santiago. n. ${ }^{\circ}$ 1744-2008. "Parra Riffo, Héctor con Rafide Morales, Juan”, 19 de agosto de 2009.

[55] Corte de Apelaciones de Santiago. Rol n. ${ }^{\circ}$ 6212-2015. “Javier Medina Casanova con Instituto de Normalización Previsional", 18 de enero de 2016.

[56] Augusto Elgueta-Ortiz, La resolución y el incumplimiento recíproco (estudio de un caso de interpretación del art. 1489 del código civil y de integración de una laguna legal mediante el procedimiento por analogía), 94, 96 y 98 (1947). (Memoria de prueba para optar al grado de licenciado en la facultad de ciencias jurídicas y sociales, Universidad de Chile). En el mismo sentido, Augusto Elgueta-Anguita, Resolución de contrato y excepción de pago Ed. Jurídica de Chile, 97 y ss. (1981) y Fabricio Mantilla-Espinosa, op. cit., 282.

[57] "Al deducir la resolutoria, la demandante pretende, en realidad, una restitución. El recurso del tribunal al espíritu general de la legislación y a la equidad natural (artículo 24 del Código civil) es, en realidad, una aplicación del principio de que nadie puede enriquecerse injustamente a costa de otro al supuesto de incumplimientos recíprocos, cuando una parte ha dado o pagado algo en virtud del contrato que pide resolver y lo que se pretende con la resolución es obtener una restitución que la otra parte se niega a hacer"; María Sara Rodríguez-Pinto, El principio 'Nadie debe hacerse más rico en detrimento de otro' (D.12, 6, 14) en la resolución de un contrato de promesa por incumplimientos reciprocos: una tendencia jurisprudencial chilena, en Estudios de Derecho Civil II, 33-34 (2006).

[58] "Por lo demás, la prescindencia de la mora como requisito de la acción resolutoria es coincidente con la tendencia del nuevo derecho de los contratos a considerar el incumplimiento como un hecho objetivo, desprovisto de consideraciones subjetivas relativas a la culpa, a las que necesariamente conduce la mora, al ser conceptualizada ésta como el retardo imputable en el cumplimiento de una obligación, después que el deudor ha sido requerido o interpelado por el acreedor. (...) La mora y la excepción de contrato no cumplido son instituciones distintas, pese a que en nuestro medio se tiende a confundirlas. Los artículos 1551 y $1552 \mathrm{CCCh}$. regulan la primera, en tanto que la segunda carece de regulación positiva, aun cuando no cabe duda que nuestro sistema jurídico la acoge. Si se lee detenidamente los artículos 1551 y 1552 CCCh., se observa que ambos regulan la mora. El primero establece la forma de constituir al deudor en mora y el segundo prescribe que la mora de uno de los contratantes purga la del otro. Ninguna de esas disposiciones regula la excepción de inejecución; una cosa es prescribir que la mora de una de las partes purga la de la otra, pero cosa distinta es autorizar derechamente a una de las partes a abstenerse de ejecutar su prestación en tanto la otra no la cumpla o se allane a hacerlo". Bruno Caprile-Biermann, op. cit., 79-80 y 82; En el mismo sentido: Mario Clemente-Meoro, op. cit., 346-349 y II Luis Di\#ez-Picazo, Fundamentos de derecho civil patrimonial, Ed. Civitas, 622-625 (1996).

[59] Así se aprecia en el fallo: "Que, fundada en principios de equidad, buena fe y en la teoría de la causa, la inejecución atribuida al acreedor demandante en el caso sublite incide en una obligación relevante, de real trascendencia en el contrato cuyo incumplimiento en lo concerniente a las especificaciones técnicas convenidas llegaron al extremo que las tolvas objeto del contrato resultaron ulteriormente inservibles para los fines que le son propios”; Corte Suprema de Chile. Rol n. $3789-2009$. "Fuentes Rodríguez, José Belisario con Canteras Lonco S.A.", 24 de marzo de 2011.

[60] Bruno Caprile-Biermann, op. cit., 77; Claudia Mejías-Alonzo, La excepción, un análisis de su aplicación en la jurisprudencia nacional reciente, op. cit., 136-138; Mario Clemente-Meoro, op. cit., 179.

[61] Con todo, para este caso, se retornaría la antigua exigencia referida a que quien puede pedir la resolución es el contratante diligente -el que cumplió lo pactado o está llano a hacerlo-.

\section{Licencia Creative Commons CC BY 4.0}

Para citar este artículo/To cite this article: Íñigo Andrés de la Maza-Gazmuri, \& Álvaro Vidal-Olivares, La excepción de contrato no cumplido. Algunas cuestiones relativas a su supuesto de hecho y consecuencias jurídicas, 68 Vniversitas, n. 139 (2019). https://doi.org/10.11144/Javeriana.vj139.ecnc 